\title{
FIBROBLAST AND OSTEOBLAST ADHESION AND MORPHOLOGY ON CALCIUM PHOSPHATE SURFACES
}

\author{
L. C. Baxter ${ }^{1}$, V. Frauchiger ${ }^{2}$, M. Textor ${ }^{2}$, I. ap Gwynn ${ }^{3}$ and R. G. Richards ${ }^{1 *}$ \\ ${ }^{1}$ Interface Biology, AO Research Institute, Davos, Switzerland \\ ${ }^{2}$ Laboratory for Surface Science and Technology, ETH, Zürich, Switzerland \\ ${ }^{3}$ Institute of Biological Sciences, The University of Wales, Aberystwyth, Wales
}

\begin{abstract}
Implant loosening in bone fixation is an unresolved complication associated with internal fixation. It is generally accepted that this problem can be overcome by modifying the implant/bone interface for improved osseointegration. This is achieved, in part, by hydroxyapatite (HA) or tricalcium phosphate coatings. Unfortunately, the benefits of these coatings are constrained by not only the generally low strength of their adhesion to the implant surface but also the limited cohesion within their layers. Anodic Plasmachemical treatment (APC) has been developed to incorporate electrolytes and produce coatings with various microtopographies and strong adhesion to implants. In this in vitro study fibroblast and osteoblast morphologies and adhesion to various substrates were evaluated using qualitative and quantitative methods. The substrates were Thermanox plastic and commercially pure titanium. The latter were surface-treated using several different methods: conventional anodisation, plasma spraying of HA and anodic plasma-chemical (APC) treatment in an electrolyte solution containing either calcium and phosphate (APC$\mathrm{CaP}$ ) or phosphoric acid (APC-P). Both osteoblasts and fibroblasts showed extensive cell spreading, total cell area and greatest amount of adhesion, with defined adhesion patterns on the Thermanox plastic, anodised titanium, and the two APC-CaP substrates. With fibroblasts, almost no cell spreading and very low adhesion, was observed in cells cultured on the APC-P and HA surfaces. The extent of cell spreading correlated with the area of focal adhesions as assessed by the amount of vinculin labelling. The Thermanox plastic, anodised titanium, and the two APC$\mathrm{CaP}$ substrates were the most cytocompatible substrates with regard to this in vitro evaluation.
\end{abstract}

Key Words: scanning electron microscopy, backscattered electron imaging, immunocytochemistry, image analysis, cell adhesion, vinculin, focal adhesions, calcium phosphate.

\author{
*Address for correspondence: \\ R.G. Richards \\ AO Research Institute, \\ Clavadelerstrasse, CH7270, Davos, Switzerland
}

Telephone number: ++41 (0) 814142397

E-mail: geoff.richards@ao-asif.ch,

http://www.aofoundation.org/ari/research/interface/index.shtml

\section{Introduction}

The control and consequences of cell adhesion are fundamental factors in many processes such as embryonic development, the immune response, maintenance of tissue and wound healing. They are especially important in the context of implants and are considered to be determining influences in their success or failure (Albrektsson et al., 1981).

Fibrous encapsulation is known to occur to implants made of steel, usually with the presence of a liquid filled void between the tissue and implant (Woodward and Salthouse, 1986) and is thought to be due to the cells not adhering adequately to the surface (Richards, 1996), resulting in a destabilisation of the implant, an inhibition of tissue regeneration and repair as well as increasing the chances of infection (Albrektsson et al., 1981; Gristina, 1987; Brunette and Chehroudi, 1999). This invariably leads to the rejection and failure of the implant. Studying the attachment and adhesion of cells to implant surfaces will enable an assessment of the relative cytocompatibility of the material being used and by selecting materials that show increased cytocompatibility more favourable biocompatibility reactions may be obtained in vivo.

The mechanism by which hard tissue becomes integrated with an internal implant is complex and involves several stages. One possible scenario follows: Cells will migrate to and attach to an implant within 3 days of implantation (Schwartz and Boyan, 1994). In vivo, the cells encountering the implant are of an undifferentiated mesenchymal origin cell type (Schwartz and Boyan, 1994). Modification of the substrate surface is initiated once the attached cells begin to secrete their own matrix (Schwartz et al., 1999) and the cells should start to differentiate into osteoblasts after 3-6 days (Schwartz and Boyan, 1994). Matrix calcification occurs between 6-14 days and bone remodelling after 21 days (Schwartz and Boyan, 1994). These cellular events occur at an accelerated rate in vitro. Cells settle on the surface of a culture dish or an introduced material within minutes (Curtis, 1964) and strong adhesions are seen within 24 hours (Van Kooten and Von Recum, 1999), though may occur within minutes. Cell attachment and adhesion play an important role in how cells react to the material they are attached to. Many anchorage dependant cells, such as fibroblasts and osteoblasts, require adhesion formation for survival. It appears to be the initial attachment of cells that regulates their subsequent behaviour and in vitro studies allow a closer examination of events at the cellular level, using a variety cell types. There are two main types of cell adhesion, adhesion to neighbouring cells and adhesion to an extracellular ma- 
trix (ECM) or to proteins absorbed onto a substrate. Cell adhesion is mediated by several different types of transmembrane receptor proteins connected to the cytoskeleton of the cell. One of the primary mechanisms of cell adhesion to a substrate, investigated in this study, was focal contacts (Curtis, 1964), also known as focal adhesions or adhesion plaques (Burridge and Fath, 1989), attached to either adsorbed proteins or the ECM. Focal adhesions are discrete regions in the cell membrane, intimately associated with the substrate, approximately $0.1-2 \mu \mathrm{m}$ wide and 2-10 $\mathrm{m}$ in length (Heath and Dunn, 1978). The distance separating the membrane and the substrate in the region of the focal adhesions approaches 10-15nm (Curtis, 1964; Cornell, 1969).

Focal adhesions consist of a complex of different molecules linking the cytoskeleton to the external environment, allowing the cell to adapt to the surface, as required. The transmembrane component of focal adhesions are the $\alpha$ and $\beta$ subunits of integrin receptors. The intracellular components of the focal adhesion complex, including talin, $\alpha$ actinin, vinculin and paxillin (Burridge et al., 1988) as well as focal adhesion kinase, a signal transduction molecule (Okumura et al., 2001), link the integrin receptors to the actin cytoskeleton of the cell. This results in a directed positioning of the filaments responsible for the contractile mechanisms of the cell (Geiger et al., 1980) and as such affects the cytoskeleton, cell shape and the behaviour of cells (ap Gwynn, 1994). The cell morphology can thus reflect the degree of adhesion of the cell onto the substrate and can be used as a parameter for measurement.

Cell morphology and adhesion were both investigated in this study to assess the relative biocompatibility of different substrates in an in vitro environment. The behaviour of both fibroblasts and osteoblasts was studied. Fibroblasts are the predominant cells found in loose connective tissue and are important in wound repair mechanisms: fibrous encapsulation is caused by the fibroblast type cells adhering to their neighbours rather than the substrate (Brunette and Chehroudi, 1999). Fibroblasts play a role in producing many of the components essential to connective tissue, for example extracellular components such as glycosaminoglycans and, in fibrous tissue, collagen (Rae, 1981). Promoting the attachment of fibroblast cells would aid in integrating soft connective tissue to the implant, improving vascularity at the implant surface and decreasing the chance of fibrous encapsulation and bacterial infection (Richards, 1996).

Osteoblasts are important cells in the osseointegration of bone to the implant. Osteoblasts are derived from undifferentiated mesenchymal stem cells (Davies, 1996). They have the ability to synthesize and produce extracellular matrix and to control its mineralisation (Brunette and Chehroudi, 1999) and thus regulate the ingrowth of bone to the implant. Osteoblasts are key cells with regard to implant performance and assessing their behaviour on a potential biomaterial may give insight into its likely biocompatibility.

The morphology of the cells assessed in terms of the degree of cell spreading, as well as an estimation of the cells areas were used as a means of comparing the effects of the different surfaces. Adhesion was also assessed in fibroblasts using an immunolabelling technique (Richards et al., 2001; Owen et al., 2001) to localise the position of vinculin, an integral focal adhesion protein. Vinculin was originally employed to investigate focal adhesions using fluorescence microscopy techniques (Hunter et al., 1995; Richards et al., 1995a), silver enhanced immunogold labelling for light microscopy (Richards et al, 1995a) and silver enhanced immunogold labelling for electron microscopy (Richards et al., 1997, 2001). Vinculin is an ubiquitous, cytoplasmic protein, with a molecular weight of $130 \mathrm{kD}$ (Geiger et al., 1984) found in many different cell types (Geiger, 1999). Vinculin was ideal for this type of study due to its presence at the time of fixation, 24 hours after seeding. Vinculin appears within 3 hours of cell attachment (Könönen et al., 1992). Internal reflection microscopy has been performed to confirm that adhesion sites imaged by scanning electron microscopy (SEM) are focal adhesions and that both they and the vinculin are able to withstand the necessary immunolabelling, fixation and embedding procedures for visualisation using SEM (Richards et al., 2001). The aim of this investigation was to localise vinculin using immunogold-labelling techniques and to assess the adhesion of osteoblasts and fibroblasts to Thermanox, Ti, hydroxyapatite (HA) coated Ti or anodic plasma-chemically (APC) treated Ti. The adhesion and morphology of cells was then used as an indication of the relative cytocompatibility of the different substrates in vitro and used to postulate on their possible biocompatibility in an in vivo situation.

\section{Materials and Methods}

\section{Substrate and surface preparation}

$13 \mathrm{~mm}$ discs for the cell culture tests were prepared with the following materials: Pre-sterilised polyethylene terephthalate (Thermanox; Nunc Inc., Naperville, IL, USA) and commercially pure titanium (CpTi) (ISO 5832/2) surface-treated according to one the following processes. All CpTi samples were first cleaned in an etching mixture of nitric and hydrofluoric acid.

a) Electrochemical anodisation in sulphuric/phosphoric acid (performed at $57 \mathrm{~V}$ ) as used for the surface treatment of orthopaedic fixation plates (sample code: ANOD);

b) Chemically deposited HA (Stratec Medical, Oberdorf, Switzerland), (code: HAbmim);

c) Anodic plasma-chemical (APC) treatment under galvanostatic conditions in an electrolyte solution containing calcium $(0.1 \mathrm{M})$ and phosphate $(0.05 \mathrm{M})$, electrolyte temperature of $25^{\circ} \mathrm{C}$, current of 200 or $290 \mathrm{~mA}$, coating time: 90 s, (code: APC-CaP);

d) Anodic plasma-chemical treatment under galvanostatic conditions in a $0.01 \mathrm{M}$ orthophosphoric acid electrolyte, electrolyte temperatures of either 25 or $75^{\circ} \mathrm{C}$, current of $290 \mathrm{~mA}$, process duration of $90 \mathrm{~s}$, (code: APC-P).

Full details of the APC surface modification technique and sample preparation techniques have been published elsewhere (Frauchiger, 2002). The discs were sterilised by gamma-irradiation sterilisation, which is used as the standard for SYNTHES ${ }^{\circledR}$ (Chur, Switzerland) metal orthopaedic implants. 


\section{Cell culture techniques}

Balb/c 3T3 fibroblasts and rat calvarial primary osteoblasts were maintained according to the method of Elvin and Evans (1982). Stock cultures were recovered from liquid nitrogen and plated at 300,000 cells per $25 \mathrm{~cm}^{2}$ plastic flask in Dulbecco's modified Eagle's medium (DMEM) with $10 \%$ foetal calf serum, without antibiotics. After 3 days, for fibroblasts, or 6 days for osteoblasts, cells were detached as follows. Fibroblasts were detached with $0.25 \%$ trypsin and $0.02 \%$ ethylenediamine tetra-acetic acid (EDTA), disodium salt - calcium and magnesium free, in tyrode buffered saline solution (TBSS). Osteoblasts were detached using TBSS containing trypsin at $0.5 \mathrm{mg} / \mathrm{ml}$ and collagenase Type 2 at $1.03 \mathrm{mg} / \mathrm{ml}$. Both fibroblasts and osteoblasts were recovered, rinsed and cultured on the 13 $\mathrm{mm}$ discs produced in the different materials and surfaces as described in the preceding paragraph. Cells were seeded at an inoculum of 20,000 cells per well for 24 hours, during which time the cells did not become confluent

\section{Fixation for morphology studies}

All chemicals were purchased from Fluka Chemie AG (Buchs, Switzerland) unless otherwise stated. All procedures were carried out at $22-25^{\circ} \mathrm{C}$. The buffer used was Piperazine-N'N'-bis-2-ethane sulphonic acid (PIPES) at a concentration of $0.1 \mathrm{~mol} \mathrm{1}^{-1}, \mathrm{pH} 7.4$ unless otherwise stated. The cells were initially rinsed for 2 minutes in PIPES buffer before being fixed in $2.5 \%$ glutaraldehyde in PIPES for 5 minutes. The cells were rinsed three times for 2 minutes each rinse in PIPES buffer. The cells were post-fixed with $0.5 \%$ osmium tetroxide (Simec Trade AG, Zofingen, Switzerland) in PIPES buffer, pH 6.8, for 60 minutes. The cells were then rinsed three times in ultra-high purity (UHP) water for two minutes each wash.

\section{Immunocytochemistry}

The immunolabelling method was based on the method developed by Richards et al (2001). The cells were initially rinsed three times for 1 minute each wash in PIPES buffer. In order to remove the cell membrane and most of the cytoplasm the cells were then permeabilised in $0.1 \%$ Triton X-100 detergent in PIPES for 1 minute. The cells were fixed in $4 \%$ paraformaldehyde in PIPES buffer for 5 minutes and washed three times for 2 minutes each wash in PIPES to remove any unreacted aldehyde. Non-specific binding sites were blocked with $1 \%$ bovine serum albumin (BSA British Biocell International (BBI), Cardiff, U.K.) and $0.1 \%$ Tween 20 in PIPES buffer for 30 minutes. Cells were then incubated with mouse anti-human vinculin (clone hVin-1 Sigma, St. Louis, MO, U.S.A) 1:300 diluted in PIPES buffer $+1 \%$ BSA $+0.1 \%$ Tween 20 for 1 hour. All tests were performed with a negative control, i.e. omitting the primary antibody. Cells were rinsed six times for 1 minute each wash in PIPES $+1 \%$ BSA $+0.1 \%$ Tween 20 . Non-specific binding sites were blocked with $5 \%$ goat serum $+1 \%$ BSA $+0.1 \%$ Tween 20 in PIPES buffer for 30 minutes. The cells were labelled with goat anti-mouse $5 \mathrm{~nm}$ gold conjugate (Auroprobe-Amersham Pharmacia (AP) Biotech, Bucks, England) diluted 1:200 in PIPES buffer + $1 \%$ BSA $+0.1 \%$ Tween 20 for 2 hours. Samples were then washed three times in PIPES buffer for 2 minutes each wash and then fixed in $1 \%$ glutaraldehyde in PIPES for 5 minutes and rinsed three times for 2 minutes each wash in PIPES buffer. The cells were further rinsed three times for 2 minutes each wash in UHP water to ensure removal of unreacted aldehyde. The gold labels were gold enhanced (Nanoprobes Incorporated, Yaphank, NY, USA.) for 7 minutes (Owen et al., 2001). The samples were immediately rinsed twice, to stop the gold-enhancement reaction, and washed four times for 2 minutes each wash in UHP water. Cells were post-fixed with $1 \%$ osmium tetroxide in PIPES buffer, $\mathrm{pH} 6.8$ for 1 hour. Cells were washed three times for 2 minutes each wash in PIPES buffer, pH 6.8.

\section{Dehydration and critical point drying.}

The samples prepared for the morphological study and half the samples for the immunocytochemical study, were taken through an acetone series $-50 \%, 60 \%, 70 \%, 80 \%, 90 \%$, $96 \%$ and $100 \%$ respectively for 5 minutes in each concentration, followed by three 5 minute changes of $100 \%$ acetone. Samples were critical point dried (CPD) with a Polaron E3000 or E3001 (Agar Scientific, Stansted, UK) critical point drier.

\section{Dehydration and embedding}

The remainder of the samples from the immunocytochemical study were also dehydrated using an acetone series followed by 24 hours in LR White resin (London Resin Co., London, UK), (medium hardness), to allow complete infiltration of the cells. The samples were placed in fresh resin in a silicon mould, at the bottom of $15 \mathrm{~mm}$ wells with the cells facing upward, with a drop of paraffin oil placed on top to exclude oxygen. The resin was cured thermally at $65^{\circ} \mathrm{C}$ for 16 hours.

\section{Transfer and coating}

The hardened resin blocks were removed from the silicon mould and abrasive paper used to remove excess resin from around the edge of the sample. The Thermanox discs were separated from the resin using a sharp blade to ease them off. The metal discs were removed by rapid cooling on a copper block that had been kept in nitrogen slush at $-210^{\circ} \mathrm{C}$ under vacuum (Richards et al, 1995b). The CPD specimens and the resin blocks containing the cells were mounted onto aluminium stubs. Samples prepared for the morphological study were coated with $10 \mathrm{~nm}$ of either gold/palladium (80/20) or chromium (osteoblasts and fibroblasts respectively). Both the CPD and resin samples prepared using the immunocytochemical method were coated with $10 \mathrm{~nm}-15 \mathrm{~nm}$ of carbon, respectively, by evaporation of carbon rods. All coatings were produced using a Baltec MED 020 unit (Baltec, Balzers, Leichtenstein).

\section{Microscope operating conditions}

Specimens were examined using a Hitachi s-4700 field emission SEM fitted with an Autrata yttrium aluminium garnet (YAG) backscattered electron (BSE) detector. The microscope was operated in HC (high current)-BSE detection mode as described by Richards and ap Gwynn (1995). The cells were either viewed from above, for the CPD samples, at $5 \mathrm{kV}$ accelerating voltage, or directly on 
the undersurface of the cells within the resin embedded samples, at $8 \mathrm{kV}$ accelerating voltage.

\section{Quantitative analysis of the images}

Image analysis was conducted for cells prepared for morphological study and for the immunolabelled cells embedded in resin, using PC-Image 2.2.03 image analysis software (Foster Findlay Associates, Newcastle, UK). The software was calibrated to measure actual dimensions. Cell areas of 30 cells on each substrate were measured for the morphological study. The area occupied by the gold label was measured in 20 different cells, embedded in resin, for each of the substrates tested. The measurements were assessed statistically using one-way analysis of variance (ANOVA) test followed by Tukeys post hoc test.

\section{Results}

\section{Cell morphology}

The cells tested showed distinct differences in their reactions to each of the different substrates tested. On the two APC-CaP surfaces both the osteoblasts and fibroblasts (Fig. 1a-d) were well spread with the edges of the cells becoming very thin. No difference in cell morphology was observed between the two surfaces. All the cells observed were closely associated with the substrate. The same observations were made for both osteoblast and fibroblast cells on the Thermanox plastic and the anodised titanium surface (Fig. 2c-f); however, the spreading of those cells was not as extensive as that of cells on the APC-CaP surfaces. Different morphologies were observed in cells cultured on the APC-P (Fig. 1e-h) and HA surfaces (Fig. 2ab). Very little spreading in both types of cell was observed and no differences perceived between cells on the two different APC-P substrates (Fig. 1e-h). The fibroblasts assumed a rounded morphology with numerous filopodia as well as blebs and folds in their surface membranes. Osteoblasts appeared more elongated with only slight areas of spreading at the end of long lamellipodia. Both types of cell were not closely associated with the surface of either the APC-P or the HA with most of the cell body raised above the surface. The cells on the HA surface often spanned grooves and troughs in the surface.

Although different morphologies were observed, the reactions of both the fibroblasts and osteoblasts appeared to be similar for each of the different substrates. The quantitative results confirmed this, as described in the next section.

\section{Quantitative cell morphology}

The measurement of the fibroblast and osteoblast areas on the different substrates confirmed the qualitative observations (Fig. 3). Cells on the APC-CaP, anodised titanium and Thermanox plastic had the greatest $(\mathrm{P}<0.05)$ areas of spread for both the fibroblast and osteoblast cell types (although, with the fibroblast cells, adhesion to the titanium surfaces was not significantly different from that to one of the APC-P surfaces). The APC-P and HA surfaces had the smallest cell areas $(\mathrm{P}<0.05)$ for both cell types. Cells on the two APC-CaP surfaces had very similar cell areas, quali- fied by the statistics, as did the cells cultured on the two APC-P surfaces, confirming the qualitative observations made.

\section{Immunolabelling of adhesion sites}

Only fibroblast adhesion was examined in this part of the study. The background labelling on the negative controls, with the omission of the primary antibody, was always low (not shown). The location of the label in the cells and the patterns created correlated with the results observed in the morphology study. The gold label, attached to regions of cell adhesion, was much harder to locate in cells imaged from above, than when imaged from beneath, once the cells were embedded in resin. Images from both above and beneath were studied for all samples, with the exception of the cells cultured on the HA, as the substrate could not be removed from the resin in this case, always breaking within the HA coating. Both types of APC-CaP surface (Figs. 47) showed a similar pattern of adhesion, with the gold label being located in groups mainly around the periphery of the cells and along stress fibres throughout the cells. Both the cells on the surface and the cells embedded in the resin, which provided a good replica of the substrate surface, showed that the groupings of label were often located on or around the rough 'volcano-like' structures on the substrate surface. The location and patterning of the gold label in cells on the APC-CaP surfaces was very similar to that observed in cells cultured on the anodised titanium and Thermanox plastic surfaces (Figs. 12-15). In the latter two surfaces the label was again located in groups around the periphery of the cell and along the stress fibres. In the cells on the anodised titanium surface (Figs. 12 and 13), the label was located over the slightly rougher areas in the substrate.

Cells on the APC-P treated surfaces (Figs. 8-10) showed no difference in adhesion patterns between the two substrates and also showed very similar patterns to those observed in the cells cultured on the HA surface (Fig. 11). The adhesions shown by the cells on the APC-P and HA surfaces were 'dot' adhesions with the labels spread randomly throughout the cells with very few groups observed. Occasionally, a few labels were located along stress fibres,

Figure 1 shows fibroblasts and osteoblasts respectively on various surfaces. (a-b) on the APC-CaP surface (200mA), both types of cell show a large amount of spreading and close membrane contact with the surface. The surface membrane appears smooth with very little surface structure. (c-d) Cells on the APC-CaP surface (290mA). Apart from some pores (arrow), the surfaces of the cell membranes appear smooth. (e-f) Cells on the APC-P surface $\left(25^{\circ} \mathrm{C}\right)$. Both cell types show little spreading, fibroblasts displaying a rounded morphology and osteoblasts elongated. Filopodia (F) as well as folds and blebs (B) on the surface membranes can be seen. Both types of cell appear raised above the surface. (g-h) Cells on the APC-P surface $\left(75^{\circ} \mathrm{C}\right)$ with similar morphology to cells on the $25^{\circ} \mathrm{C}$ surface. 

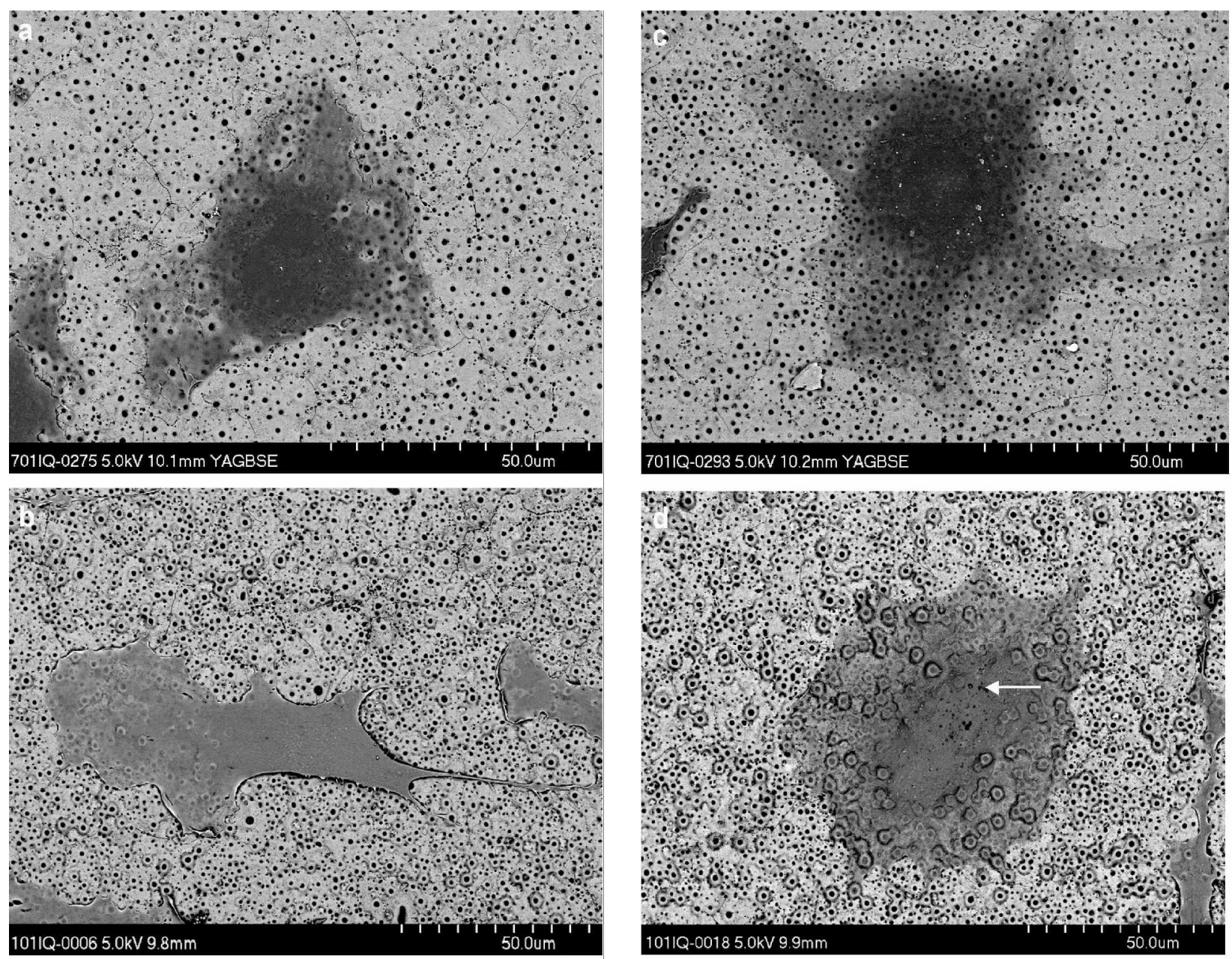

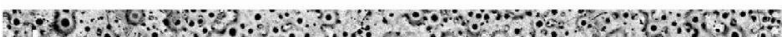
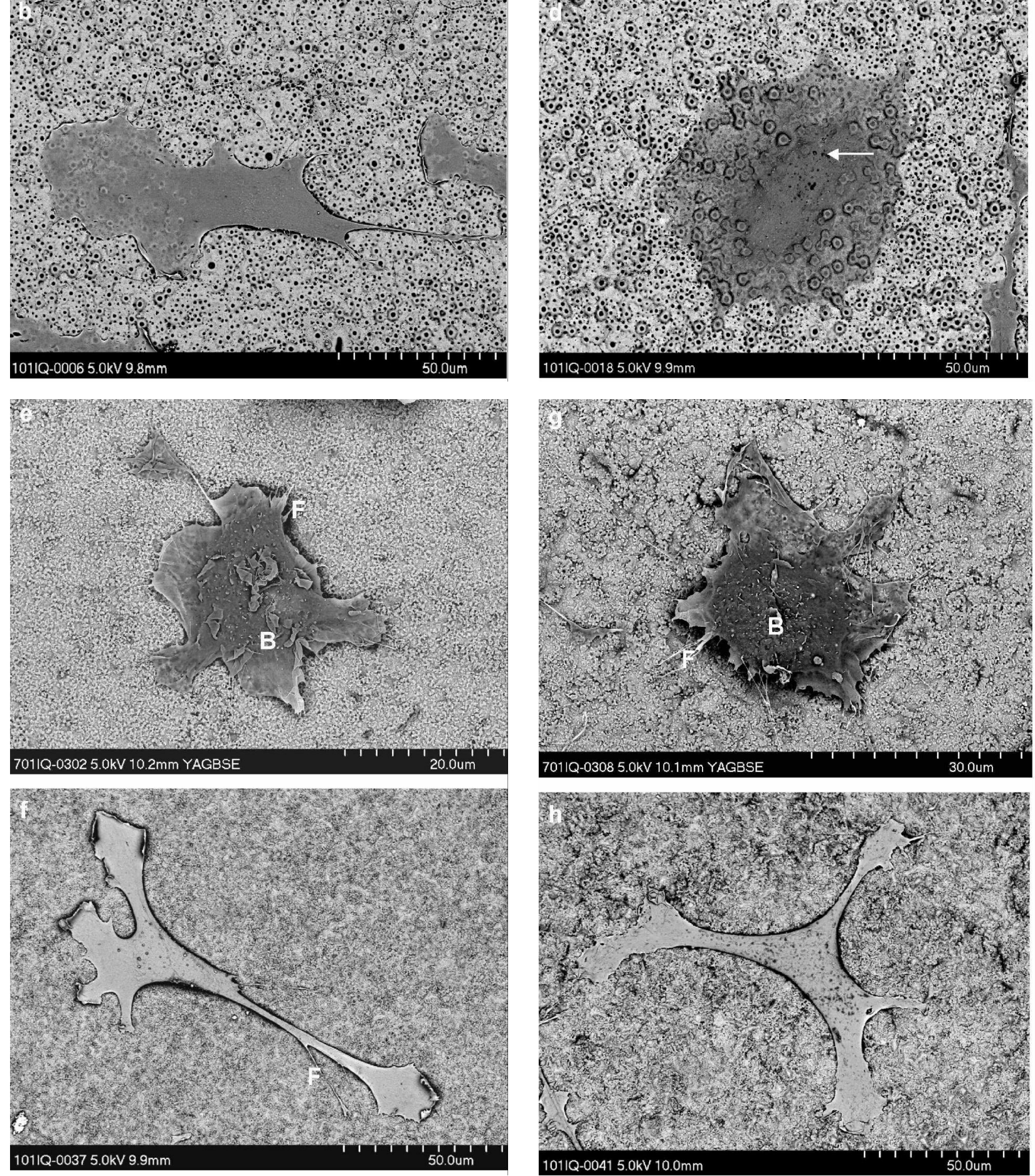

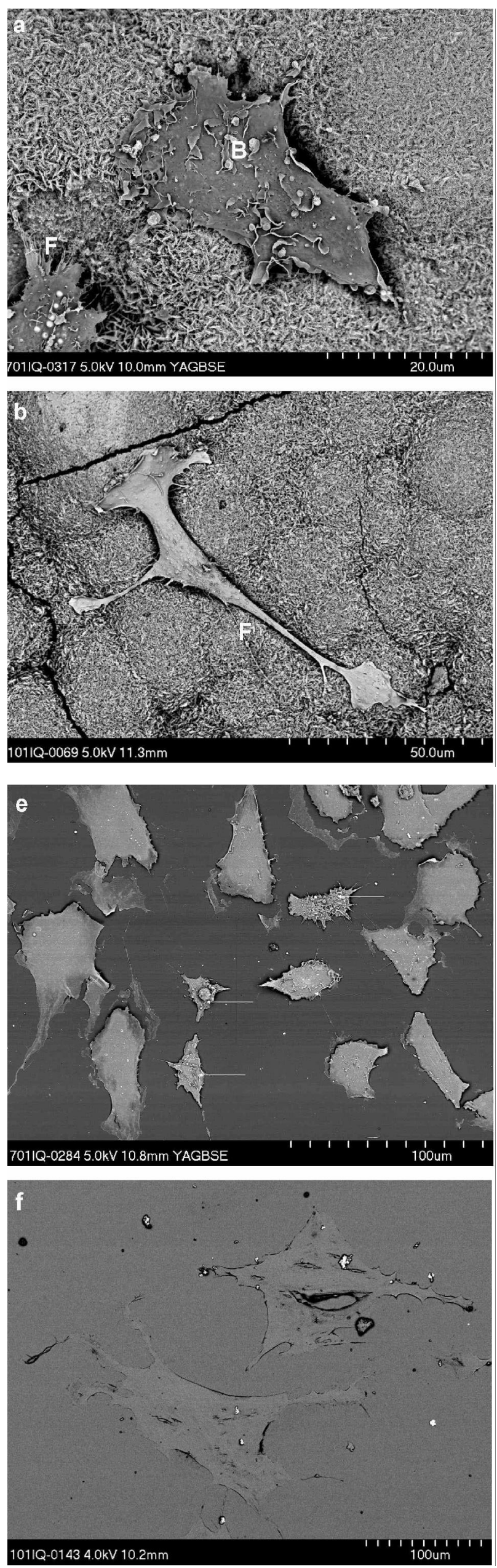
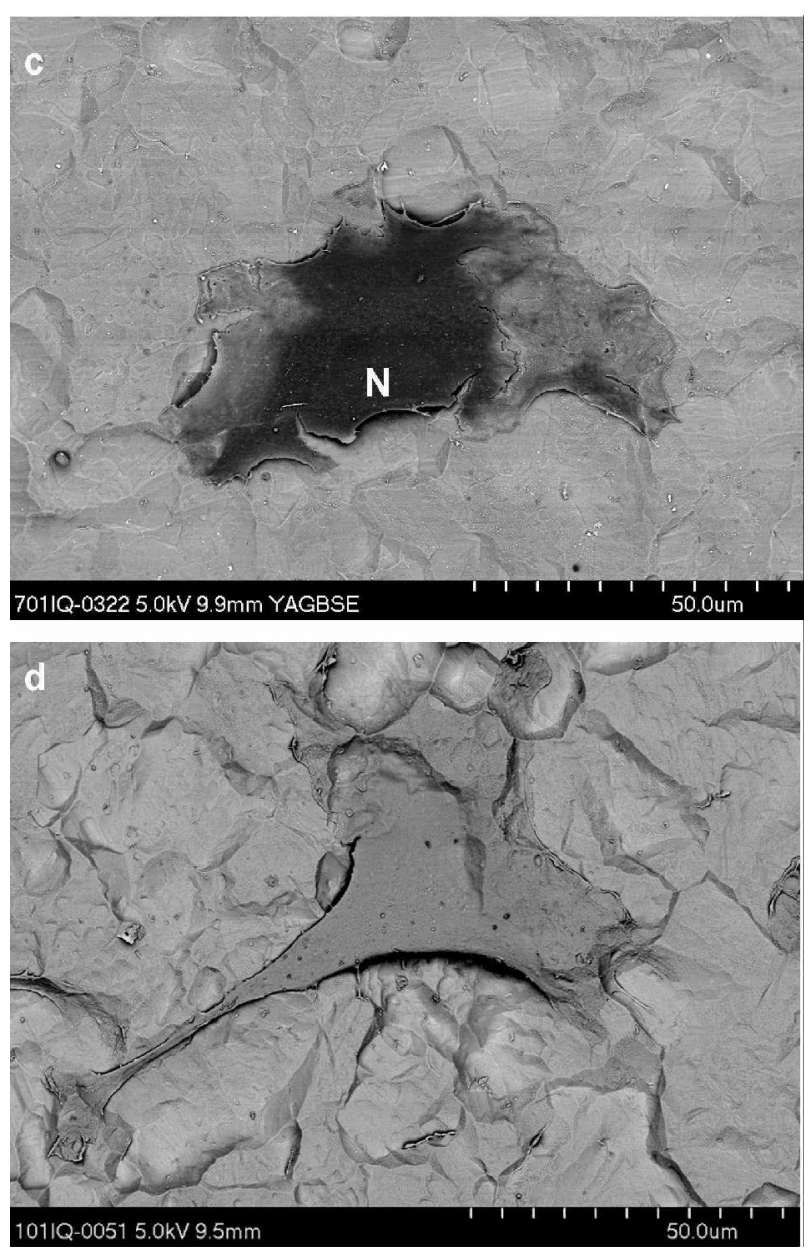

Figure 2 shows fibroblasts and osteoblasts, respectively on various surfaces. (a-b) on the hydroxyapatite surface. Very little spreading is seen for either type of cell. The fibroblasts are flattened but not spread and osteoblasts elongated. Many filopodia (F) as well as folds and blebs (B) are seen on the surface. Both cell types appear raised above the substrate surface. (c-d) Both cell types are spread with close apposition to the anodised titanium substrate. With the exception of pores the surfaces of the cells are smooth. The position of the nucleus $(\mathrm{N})$ can be identified in some of the fibroblasts. (e-f) Cells on the Thermanox plastic surface show a similar flattened morphology to those on titanium. The rounded cells shown may be in different stages in the cell cycle (arrows).

but these were rarely observed. The results from the qualitative study correlated with the quantitative results.

\section{Quantitative immunolabelling}

Measurement of cell adhesion area confirmed the qualitative observations (Fig. 16). Cells on the APC-CaP, anodised titanium and Thermanox plastic surfaces had significantly greater $(\mathrm{P}<0.05)$ areas of cell adhesion when compared to the APC-P surfaces. Due to problems in removing the HA substrate from the resin no quantitative results were obtained for adhesion to the HA surface.

The amount of cell spreading correlated with the area of focal adhesions, as assessed by vinculin labelling. The more spread cells producing larger and more organised areas of adhesion. The results showed that the APC-CaP, 
Cell area $\left(\mu \mathbf{m}^{2}\right)$ on test surfaces.

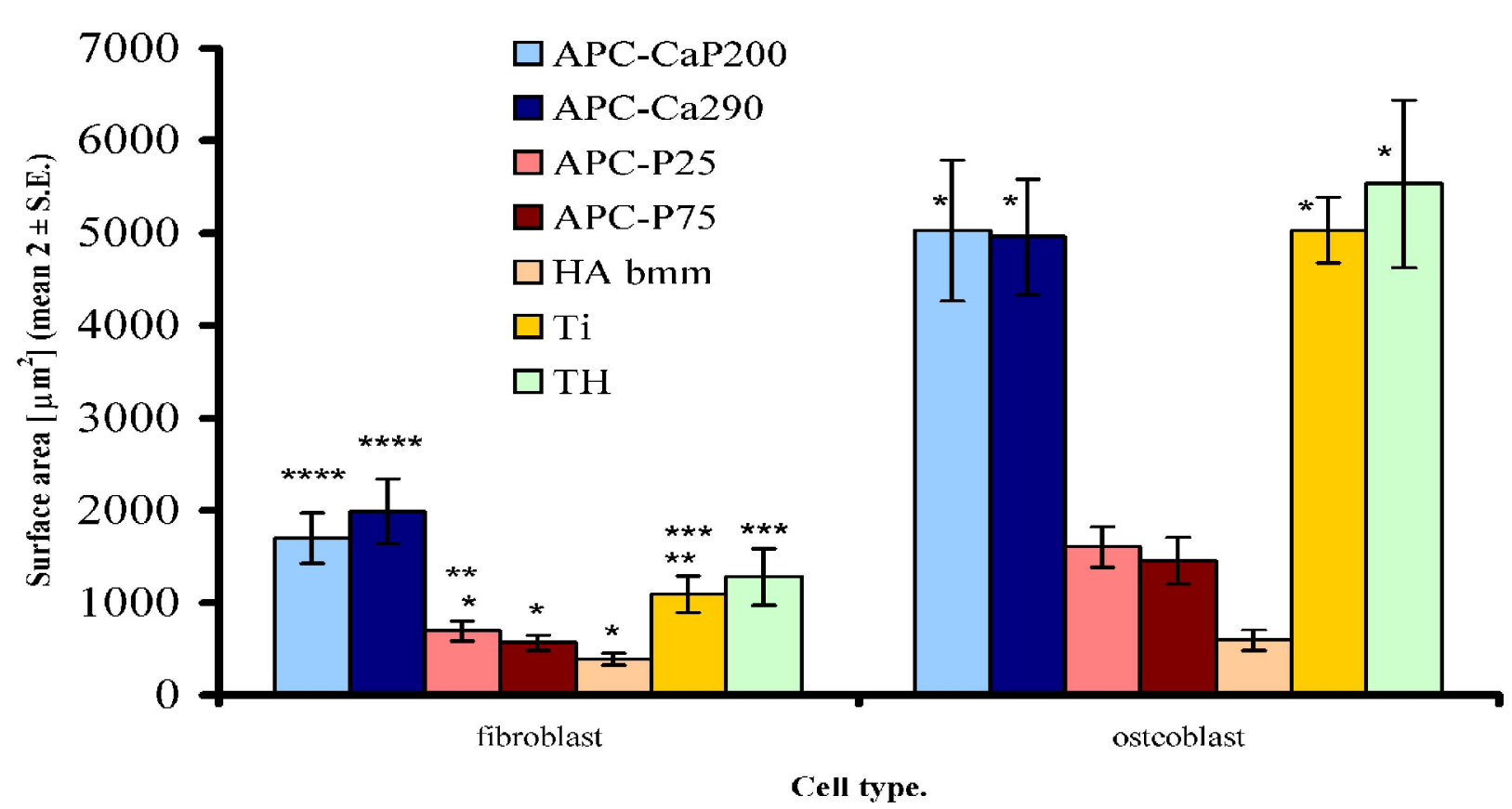

Figure 3. Graphical representation of fibroblast and osteoblast cell areas on the APC-CaP (200 and 290), APC-P (PA25 and PA75), hydroxyapatite (HA), anodised titanium (Ti), and Thermanox plastic (TH) surfaces. Both types of cell show correlation of cell areas on the different surfaces. The error bars represent twice the standard error \pm . The * indicates a significant statistical difference $(\mathrm{P}<0.05)$. The osteoblast cell areas were divided into two homogenous subsets, with a significant difference $(\mathrm{P}<0.05)$ between the areas of the cells on the APC-CaP (200 and 290), anodised titanium (Ti) and Thermanox plastic (Th) compared to the APC-P (PA 25 and 75) and hydroxyapatite surfaces (HA). The Fibroblasts were divided into four homogenous subsets. The cells on the APC-CaP (200 and 290) surfaces had significantly larger $(\mathrm{P}<0.05)$ cell areas when compared to all the other surfaces. The cell areas on the hydroxyapatite (HA) and the APC-P surfaces (PA 25 and PA75) were significantly smaller $(\mathrm{P}<0.05)$ than all the other surfaces, except that PA25 was not significantly different from titanium (Ti). The areas on titanium (Ti) and Thermanox plastic (Th) were significantly larger $(\mathrm{P}<0.05)$ than on the hydroxyapatite and one APC-P surface $(\mathrm{PA} 75)$ and significantly smaller $(\mathrm{P}<0.05)$ than on both of the APC-CaP surfaces.

anodised titanium and Thermanox plastic substrates produced a greater amount of spreading and adhesion in osteoblasts and fibroblasts, in vitro, than the APC-P and HA samples tested.

\section{Discussion}

For non-transformed cells, the shape of cells is tightly coupled to DNA synthesis (Folkman and Moscona, 1978). The amount of $3 \mathrm{H}$-thymidine taken up is inversely proportional to the height of the cell. DNA synthesis is shown to be the same for cells on a non-adhesive surface (cells are rounded) and cells in a very confluent culture (thus growth inhibited), once they have reached the same height as the rounded cells. In the present study, changes in cell adhesion in response to different substrates was linked intimately with modifications to cell morphology. Consequently, it is reasonable to expect that substrate properties would affect proliferation and differentiation of cells. These results agreed with other studies. Rodriguez Fernández et al. (1993) show that cells with very small adhesion plaques and low vinculin levels are poorly spread and have a rounded morphology.
Hunter et al. (1995) show that rounded cells have lower proliferation rates. Thus the substrates showing the greatest spreading and adhesion would appear to promote proliferation and colonisation of the surface.

Both the quantitative and qualitative assessments of cell morphology showed that osteoblasts and fibroblasts reacted in a similar manner to the different surfaces tested. For both cell types the surfaces with the high density of fine roughness discontinuities, namely the APC-P and HA surfaces, showed the least spreading and adhesion. The greatest amount of spreading in both cell types was observed on the APC-CaP, anodised titanium and Thermanox plastic, respectively for fibroblasts but with no discernable difference for osteoblasts. Increased spreading on smoother surfaces is observed in a number of different studies. Könönen et al. (1992) show, using fibroblasts, that greater cell spreading occurs on smooth electropolished titanium, than on the rougher etched or sandblasted titanium surfaces. Oakley and Brunette (1993) also show that fibroblast cells exhibit larger cell areas on smooth surfaces when compared to surfaces with grooves.

Osteoblast morphologies correlated with those shown 

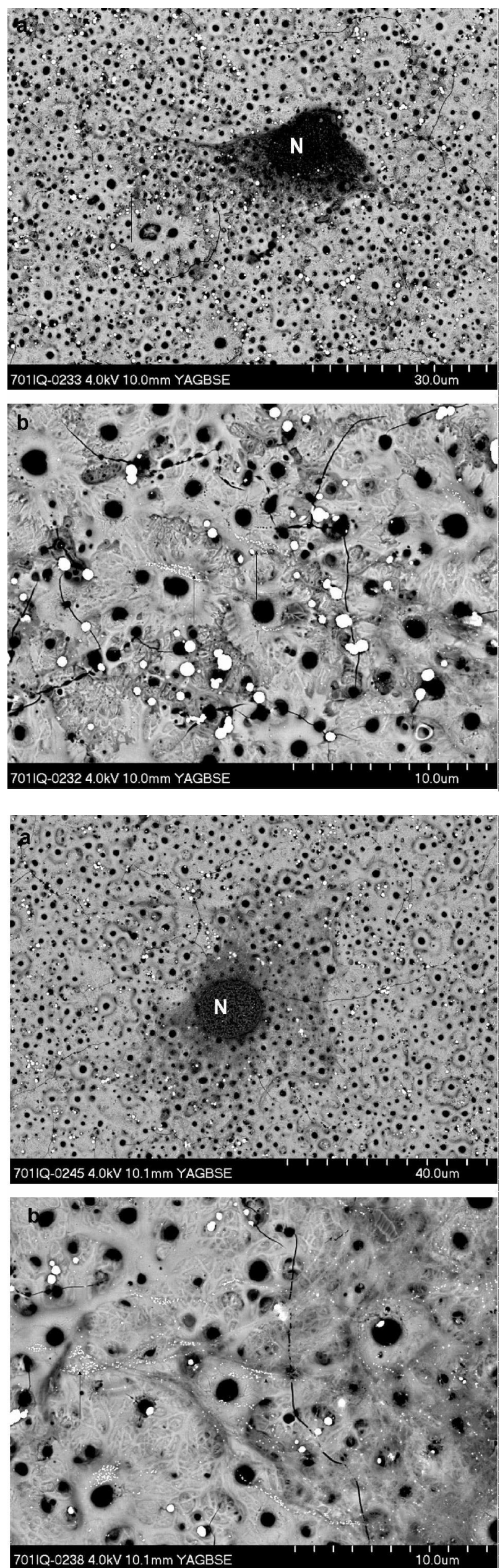
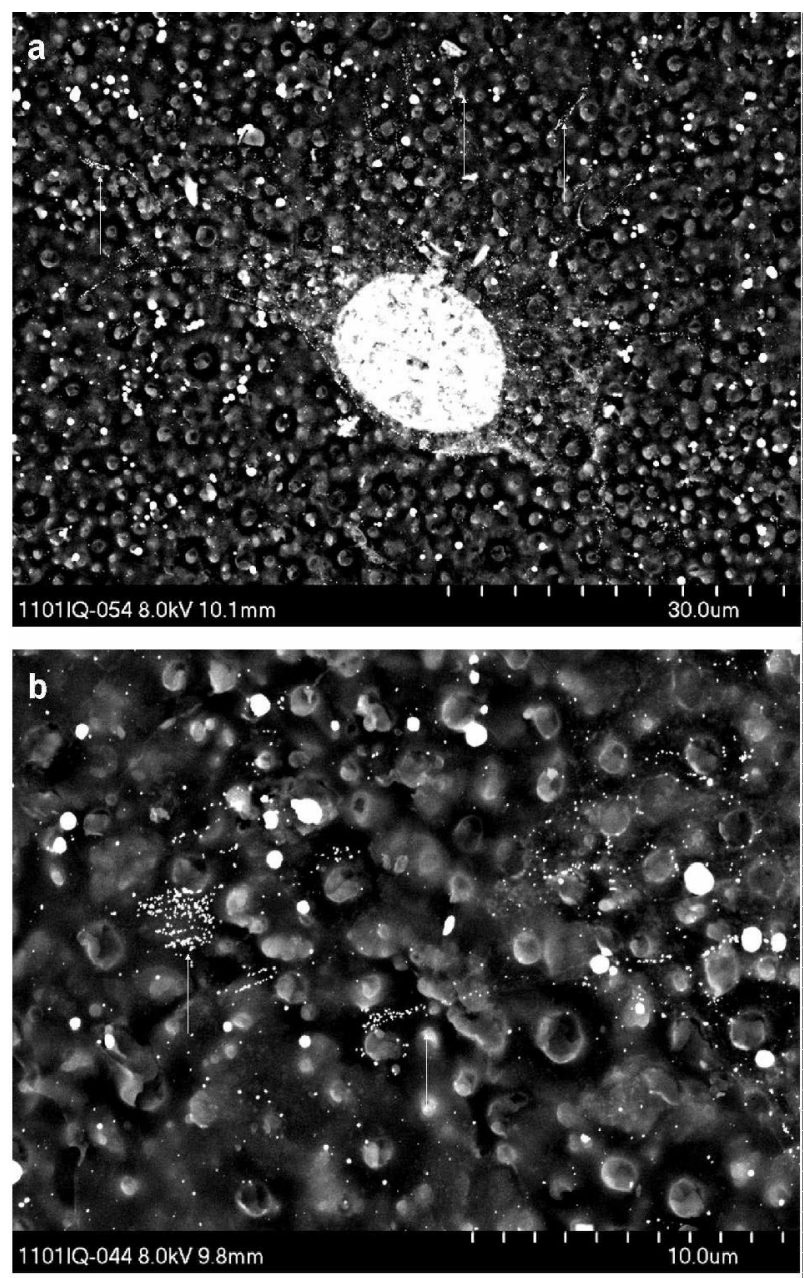

Figure 4. (a-b) Fibroblasts Figure 5. (a-b) Fibroblasts on the APC-CaP surface embedded in resin following (200mA) following the removal of the APC-CaP surimmunolabelling of face $(200 \mathrm{~mA})$ after the vinculin procedure. The la- immunolabelling procedure. belled adhesion sites cannot It is much easier to see the be seen on the lower mag- label (arrows) even at the low nification (a) but are appar- magnification of the whole ent at higher magnification cell, compared to viewing (arrows). In this example, cells direct on the surface adhesion patterns are (fig. 4).

mainly located at the cell periphery.

Figure 6. (a-b) Fibroblasts on the APC-CaP surface (290mA) following the immunolabelling procedure. The adhesion sites (arrows) are mainly located at the cell periphery and along the stress fibres. The nucleus $(\mathrm{N})$ can be easily identified. 

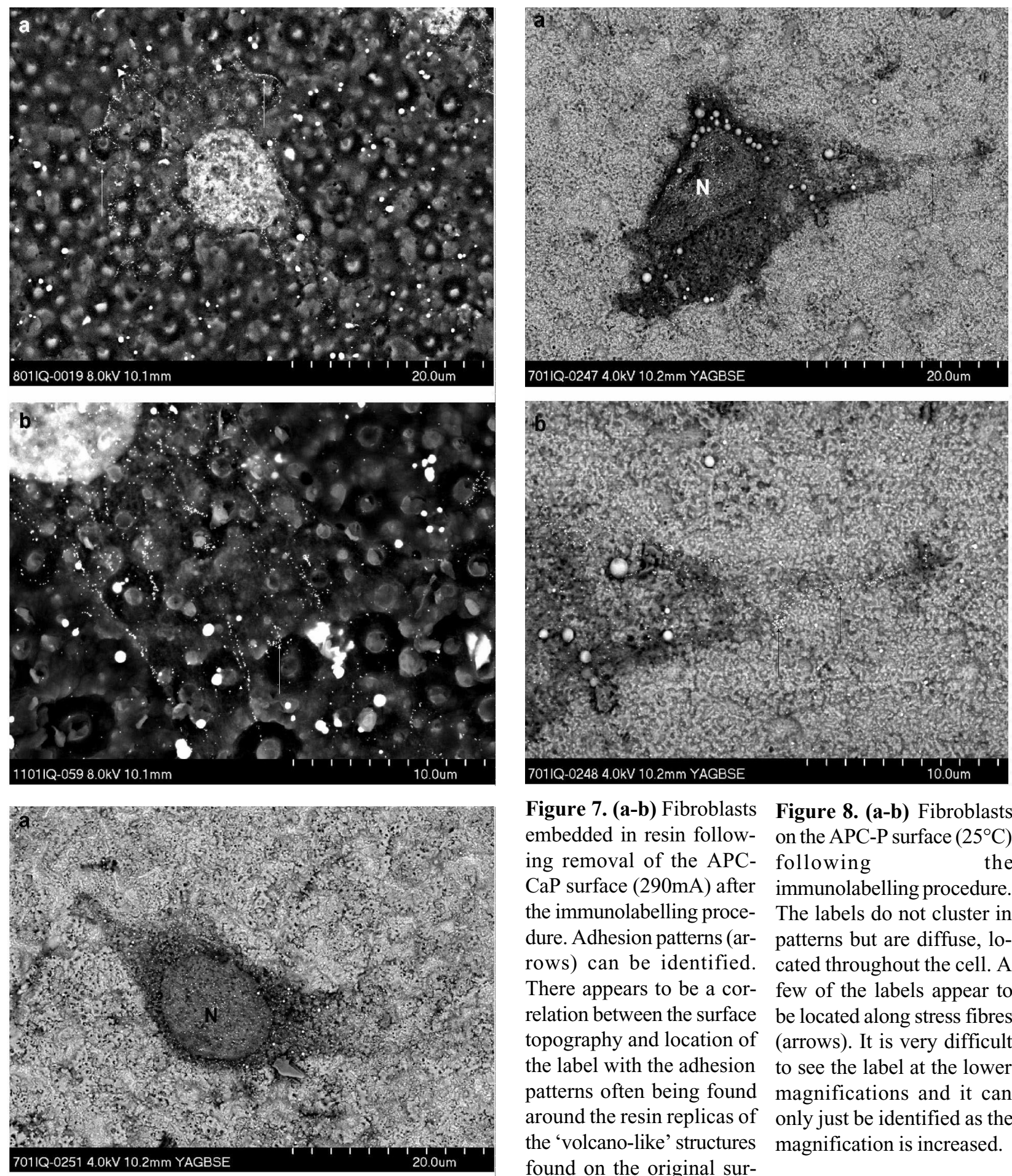

Figure 7. (a-b) Fibroblasts embedded in resin following removal of the APCCaP surface $(290 \mathrm{~mA})$ after the immunolabelling procedure. Adhesion patterns (arrows) can be identified. There appears to be a correlation between the surface topography and location of the label with the adhesion patterns often being found around the resin replicas of the 'volcano-like' structures found on the original sur-

Figure 8. (a-b) Fibroblasts on the APC-P surface $\left(25^{\circ} \mathrm{C}\right)$ following the immunolabelling procedure. The labels do not cluster in patterns but are diffuse, located throughout the cell. A few of the labels appear to be located along stress fibres (arrows). It is very difficult to see the label at the lower magnifications and it can only just be identified as the magnification is increased. face.

Figure 9. (a-b) Fibroblasts on the APC-P surface $\left(75^{\circ} \mathrm{C}\right)$ following the immunolabelling procedure. No clear patterns can be seen in the positioning of the gold label. 

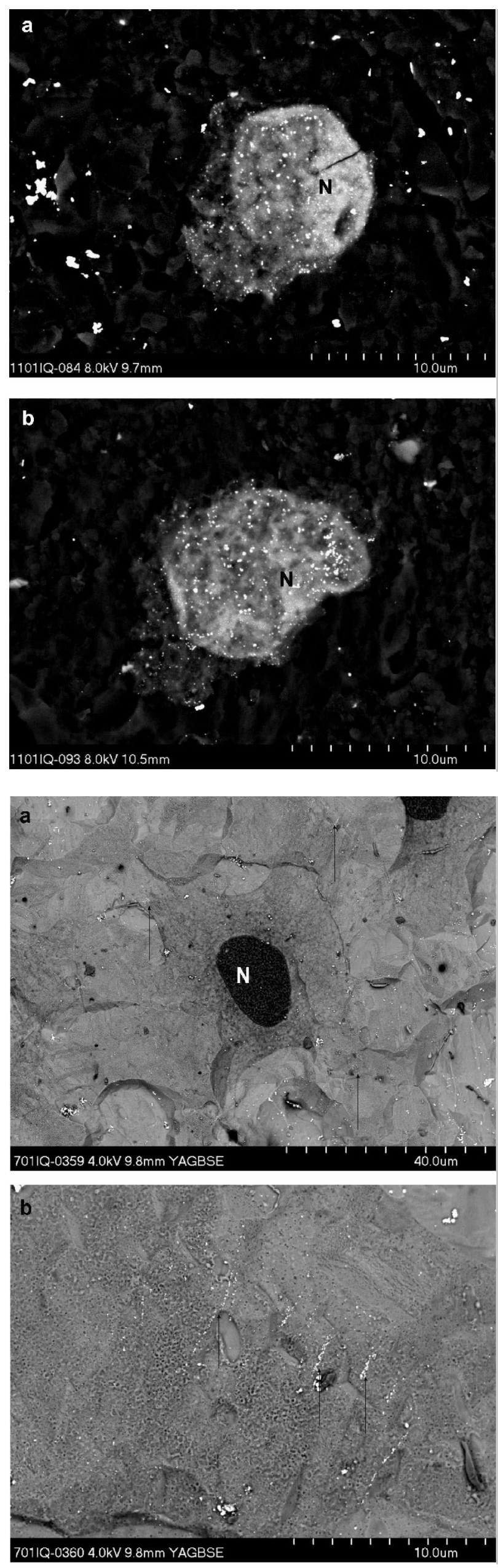
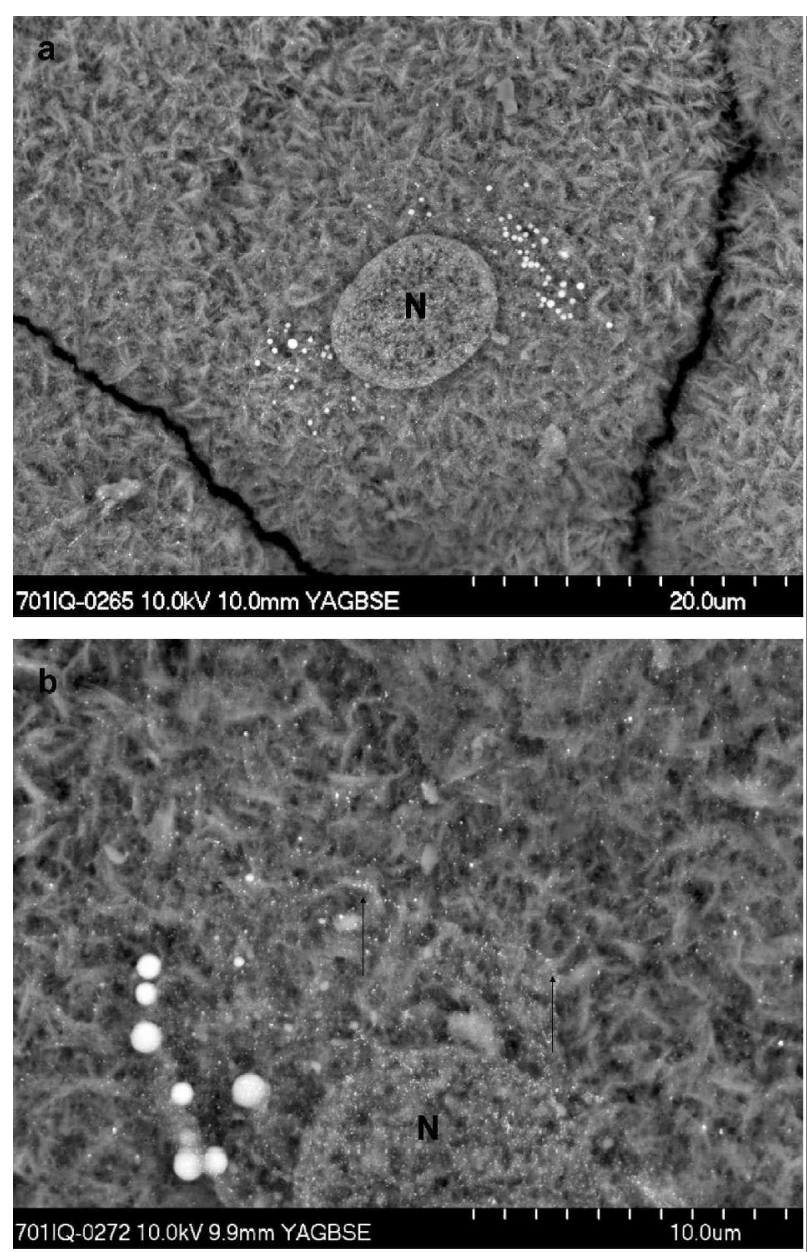

Figure 10. (a-b) Fibroblasts Figure 11. (a-b) Fibroblasts embedded in resin following on the hydroxyapatite surremoval of the APC-P sur- face following the face $\left(25\right.$ and $75^{\circ} \mathrm{C}$ respec- immunolabelling procedure. tively) after the It is very difficult to see the immunolabelling procedure. thinly spread cell edges, Since the cells are mainly with only the nucleus (N) rounded on the substrate, the being clear. On the higher whole cell could be imaged magnification no specific at a magnification that al- adhesion patterns can be lowed the labels to be clearly seen, although some very seen. There is a lack of any small clusters of label are adhesion pattern and only apparent(arrows). pinpoint adhesions observed. The nucleus $(\mathrm{N})$ is further away from the substrate compared to cells on other surfaces, due to the rounded morphology of the cells.

Figure 12. (a-b) Fibroblasts on the anodised titanium surface following the immunolabelling procedure. The label can be seen both magnifications. No background labelling is apparent on the nucleus $(\mathrm{N})$ and in the cytoplasm of the cell the label appears to be located mainly at the cells periphery (arrows). The label often coincides with areas on the surface of the titanium that have fine discontinuities in the microtopography. 

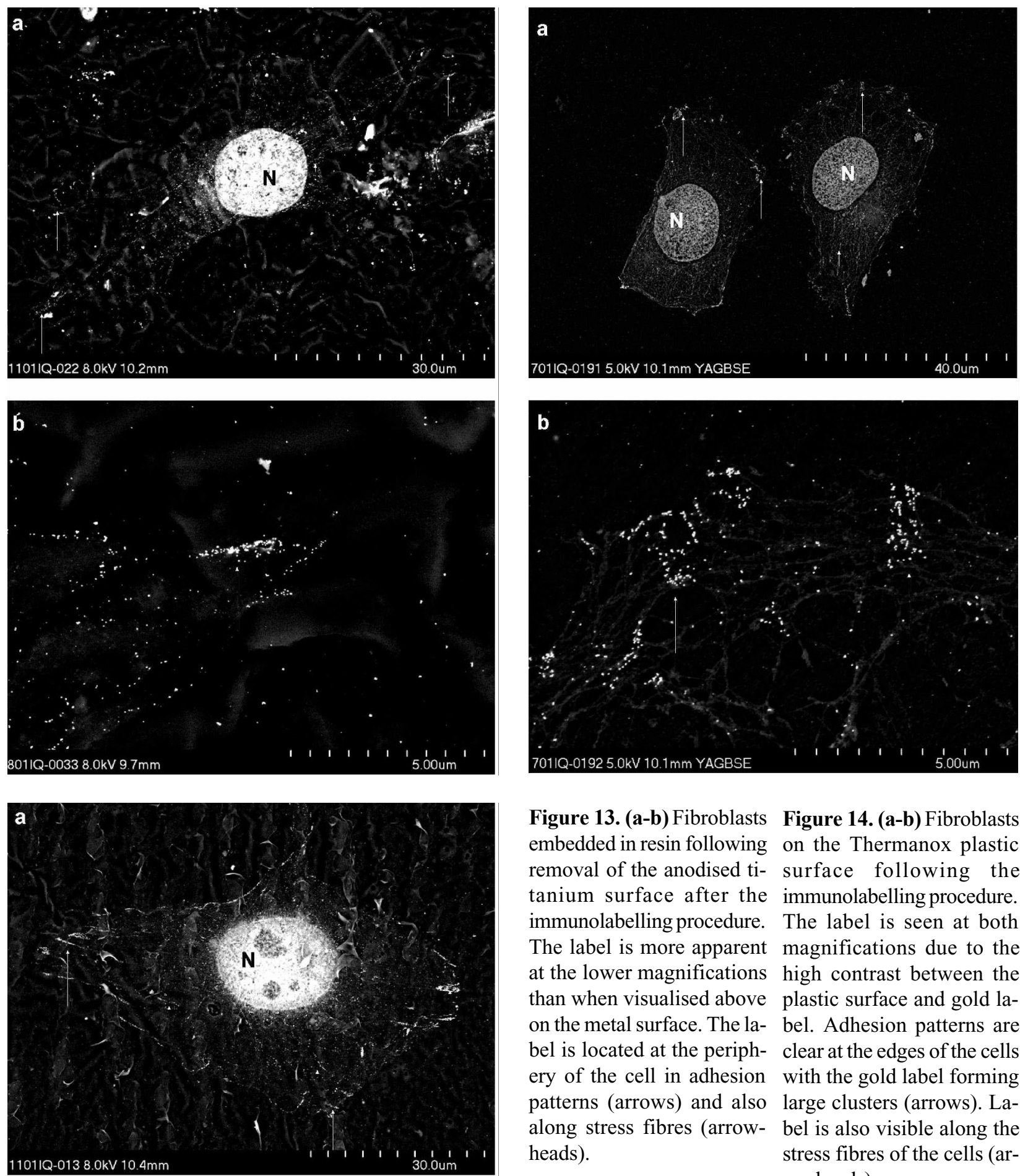

Figure 13. (a-b) Fibroblasts embedded in resin following removal of the anodised ti-

Figure 14. (a-b) Fibroblasts on the Thermanox plastic ti- surface following the tanium surface after the immunolabelling procedure. immunolabelling procedure. The label is seen at both The label is more apparent magnifications due to the at the lower magnifications high contrast between the than when visualised above plastic surface and gold laon the metal surface. The la- bel. Adhesion patterns are bel is located at the periph- clear at the edges of the cells ery of the cell in adhesion with the gold label forming patterns (arrows) and also large clusters (arrows). Laalong stress fibres (arrow- bel is also visible along the heads). stress fibres of the cells (arrowheads).

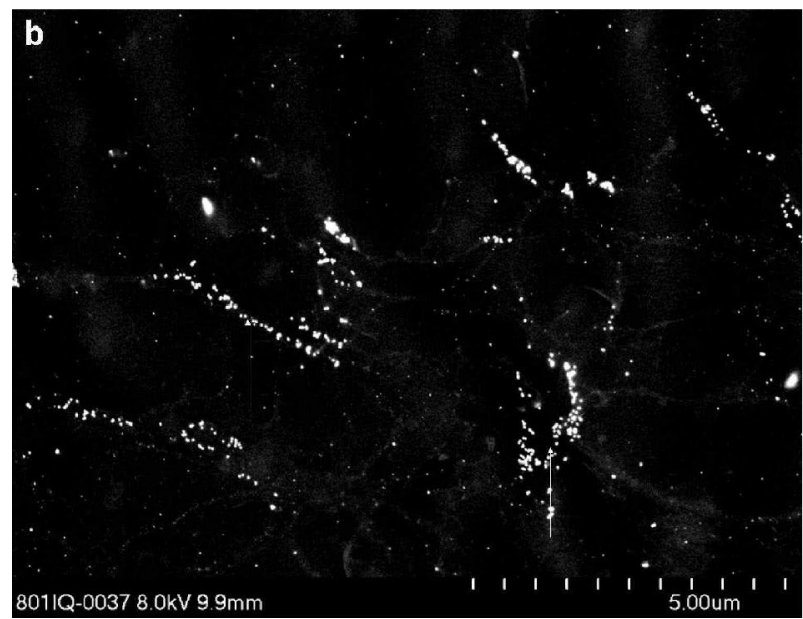

Figure 15. (a-b) Fibroblasts embedded in resin following removal of the Thermanox plastic surface after the immunolabelling procedure. The label is in large adhesion patterns at the periphery of the cells (arrows) and on the stress fibres of the cell (arrowheads). 


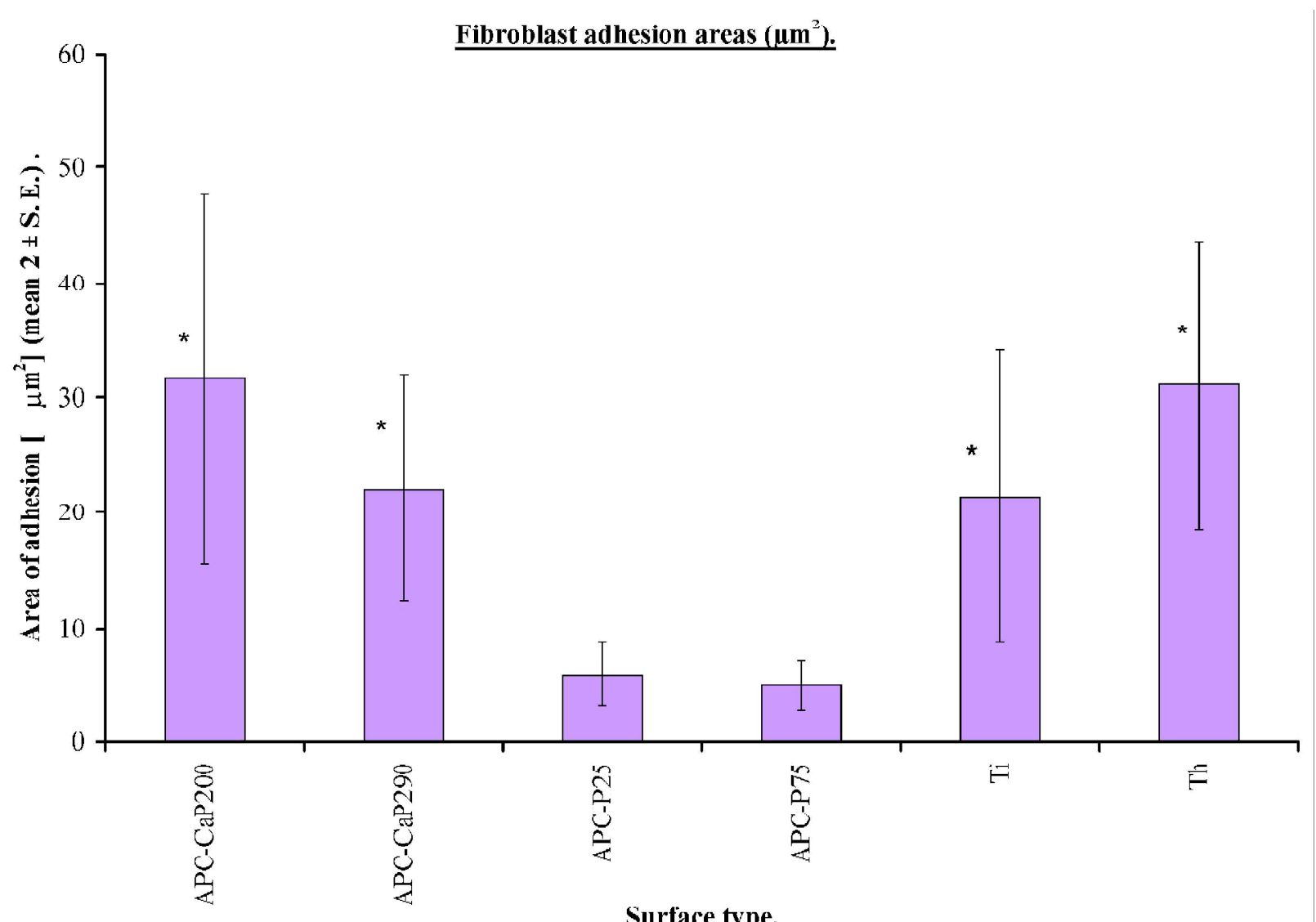

Figure 16. Graphical representation showing the areas of adhesion on the six different substrates. 200 and 290 are the APC-CaP surfaces coated at currents of 200 and 290mA; PA25 and PA75 are the APC-P surfaces coated at 25 and $75^{\circ} \mathrm{C}$; Ti is the anodised titanium surface and $\mathrm{Th}$ the Thermanox plastic (HA could not be included as the surface was not cleanly removed from the resin). The error bars represent twice the standard error \pm . The * indicates a significant difference $(\mathrm{P}<0.05)$ between the area of adhesion of cells on the different surfaces. The cells on the APC$\mathrm{CaP}$ (200 and 290), titanium (Ti) and Thermanox plastic $(\mathrm{Th})$ have a significantly greater $(\mathrm{P}<0.05)$ area of adhesion than the cells on the APC-P surfaces (PA25 and PA75).

by the fibroblasts, with greatest spreading observed on the smoother APC-CaP, anodised titanium and Thermanox plastic. Other reports show that attachment and proliferation of osteoblasts is greatest on the rougher surfaces with more irregular topographies (Schwartz et al., 1999; Degasne et al., 1999). However, there are also correlating studies, Okumura et al. (2001) shows, using osteoblasts, that after 48 hours there is a greater amount of spreading on titanium when compared to HA. Mustafa et al. (2000) shows that there is more spreading and attachment of osteoblasts on the smoothest and coarsest titanium samples, the coarsest titanium having large smooth areas (unfortunately the size of these areas is not disclosed). Other correlating studies also show that spreading and proliferation is greater for osteoblasts on smooth polished surfaces (Bagambisa et al., 1994) and that this coincides with an increase in alkaline phosphatase activity (Anselme, 2000). The discrepancies in the literature are apparent and probably related to the methods of assessment as well as the maturity of the cells used (Schwartz et al., 1996). However, most of the studies described show similar cell morphologies to those observed in this study.

Both the quantitative and qualitative assessments of fibroblast adhesion on the different substrates correlated with the results from the morphological study. Strong cell adhesion was seen on the APC-CaP, anodised titanium and Thermanox plastic substrates. Quantitatively, the fibroblasts on these substrates showed a greater area of adhesion than the cells on the APC-P surfaces (it was not possible quantitatively to assess adhesion on the HA surface). Not only was the area of adhesion different but also the pattern of adhesion was variable. The cells on the APC-P and HA surfaces showed only 'dot' adhesions, with a few small clusters of label. Occasionally, gold labels were seen attached along a stress fibre.

There are two types of focal adhesions (Bershadsky et al., 1985). 'Dot', or small preliminary contacts $(0.2-0.5 \mu \mathrm{m})$, are composed of transmembrane and linker proteins but are not associated with actin stress fibres. These are the predominant type at the active edge of the cell. Elongated large mature contacts, 'dash' contacts $(2-10 \mu \mathrm{m}$ by $0.5 \mu \mathrm{m})$ are also composed of transmembrane and linker proteins but associate with actin stress fibres. They comprise 40$50 \%$ of cell contacts and are located centrally in parts of the lamellae, endoplasm and under the nucleus. Formation of 'dot' contacts occurs initially, followed by maturation into 'dash' contacts with associations to actin stress fibres. This would suggest that the APC-P and HA surfaces pre- 
vented maturation of 'dot' adhesions to 'dash' adhesions within the 24 hour growth period, which would prevent mechano-transduction through the adhesions and stress fibres to the nucleus, since it is known that signals from the integrins are relayed to the nucleus by the bridging proteins and the actin stress fibres (Juliano and Haskill, 1993). These signals initiate nuclear gene expression that sends the corresponding response signal. Therefore, at least at the 24-hour stage, the APC-P and HA surfaces would not be able to accomplish signal transduction through this process.

In contrast to the APC-P and HA surfaces, the cells on the APC-CaP, anodised titanium and Thermanox plastic surfaces all showed large focal adhesion patterns located mainly around the periphery of the cell. This typical type of patterning is described in cells showing good adhesion (Richards et al., 1997). Vinculin also appeared to be located along the stress fibres of the cells, in classic fibrillar patterns. A highly organised cytoskeleton with stress fibres is often associated with strong cell adhesion (Badley et al, 1980). Focal adhesions are known to be located at the termini of stress fibres (Geiger et al, 1980) but vinculin is also localised along the stress fibres of osteoblasts in well spread cells (Puleo and Bizios, 1992). Fibroblasts clearly showed stronger adhesion on the APC-CaP, anodised titanium and Thermanox plastic surfaces when compared with the HA and APC-P surfaces.

The combined adhesion and morphology results suggested that the different test surfaces had critical effects on cells. According to Schwartz and Boyan (1994) there are four factors in the construction of a surface that influence cell reactions. These are composition, surface energy, roughness and topography. These are often interrelated areas and it is difficult to understand which of these, if any, most affect cell attachment. Determining which of these factors were involved was not possible in this study, due to the widely differing characteristics of each surface used. Roughness of the substrate may be an important factor in cell adhesion and spreading, as shown in several different studies. Anselme et al. (2000) show, using osteoblasts, that focal adhesions are less numerous on rough, less organised surfaces than on smoother surfaces. There is also less contact, between the cell and the substrate as the "fractal dimension", a measurement of surface roughness, is increased and results in lower cell adhesion and proliferation rates. Vinculin synthesis, shown to influence the adhesion and spreading of cells, is itself affected by the amount of adhesions the cell has with the surface (Ungar et al., 1996). These observations appeared to be confirmed by both the morphology and adhesion results, with clear reductions in the amount of attachment, contact and adhesion exhibited by cells cultured on the APC-P and HA surfaces, the surfaces exhibiting greater microroughness with regard to the microtopography, as evaluated under the field emission SEM (FESEM).

The low level of adhesion and spreading, seen in cells grown on the HA surface, were surprising. HA is thought to be biocompatible surface coating that can accelerate properties of bone healing (Chou et al., 1999). Takebe et al. (2000) show that cells on HA have a flattened spreading morphology with numerous filopodia and that they are intimately associated with the surface, but that cell adhesion is greater on commercially pure titanium at 60 and 120 minutes after introduction. Okumura et al. (2001) also demonstrate that fewer vinculin containing adhesion plaques are present in osteoblasts on HA at 12 and 24 hours, when compared to titanium. The adhesion, as well as morphology, of fibroblasts on HA confirmed these observations. The HA and APC-P surfaces did not appear as if they would support fibroblast cell adhesion in vivo, to the extent that prevention of fibrous capsule formation would occur.

The spreading of osteoblasts on the APC-CaP, anodised titanium and Thermanox plastic suggests that there was greater adhesion on these surfaces than on the APC-P and HA substrates. This might not, however, indicate that better bone integration necessarily would occur on the surfaces that induced the most spreading. Okumura et al. (2001) suggest that the lack of vinculin-containing adhesion sites in the osteoblasts on HA is because they are of a more differentiated phenotype. The differential phenotype theory is also cited in other studies (Schwartz and Boyan, 1994; Boyan et al., 1996; Takebe et al., 2000). The results from this study, however, indicated that this might not have been the case.

Anodised titanium is known to be a good surface for both in vivo (Krause et al., 2000) and in vitro (Vinall et al., 1995) cell adhesion of soft and hard tissue types, with good integration of both bone and connective tissue. Due to the similar reactions of both the fibroblasts and osteoblasts on anodised titanium and the APC-CaP surfaces, it is possible that similar surfaces would also aid integration of implants and bone tissue in vivo. The osteoblast and fibroblast morphologies of cells cultured on the APC-P and HA surfaces were vastly different from that of cells grown on titanium and as such would not support such integration. In vivo investigations, using the same surfaces as those applied in this study, have been undertaken to define the cellular response to the test surfaces and are currently under analysis.

In vitro conditions do not replicate in vivo situations, due to the large number of factors that would have to be taken into consideration. It is, however, possible to determine the basic cell reactions for a single cell type in serum in vitro. While this would not represent fully the cell reactions in vivo it could give some idea of how different cell types might respond. As a part of a cytocompatibility repertoire of tests, these methods could be used to reduce the number of surfaces tested for biocompatibility with in vivo studies.

\section{Acknowledgements}

We are grateful to Osian Meredith (Interface Biology, AO Research Institute) for help with the immunocytochemistry technique, Falko Schlotig (Stratec Medical) and Beat Gasser (Robert Mathys Foundation) for useful discussions. Partial funding of this was provided by KTI MedTech (grant number 4729.1), Robert Mathys Foundation and Stratec Medical. 


\section{References}

Albrektsson T, Brånemark P-I, Hansson HA, Lindström J (1981) Osseointegrated titanium implants. Acta Orthop Scand 52: 155-170.

Anselme K (2000) Osteoblasts adhesion on biomaterials. Biomaterials 21: 667-681.

Anselme K, Bigenelle M, Noel B, Dufresne E, Judas D, Iost A, Hardouin P (2000) Qualitative and quantitative study of human osteoblast adhesion on materials with various surface roughnesses. J Biomed Mater Res 49: 155166.

ap Gwynn I (1994) Cell biology at interfaces. J Mater Sci: Mater Med. 5: 357-360.

Badley RA, Woods A, Carruthers L, Rees DA (1980). Cytoskeletal changes in fibroblast adhesion and detachment. J Cell Sci 43: 379-390.

Bagambisa FB, Kappert HF, Schilli W (1994). Cellular and molecular biological events at the implant interface. J Craniomaxillofac Surg 22: 12-17.

Bershadsky AD, Tint IS, Neyfakh A, Vasiliev JM. (1985) Focal contacts of normal and RSV-transformed Quail cells, Hypothesis of the transformation-induced deficient maturation of focal contacts. Exp Cell Res 158: 433444.

Boyan BD, Hummert TW, Dean DD, Schwartz Z (1996) Role of material surfaces in regulating bone and cartilage cell response. Biomaterials 17: 137-146.

Brunette DM, Chehroudi B. (1999). The effect of surface topography of micromachined titanium substrata on cell behaviour in vitro and in vivo. J Biomech Eng 121: 49-57.

Burridge K, Fath K (1989) Focal contacts: transmembrane links between the extracellular matrix and the cytoskeleton. Bioessays 10: 104-108.

Burridge K, Fath K, Kelly T, Nuckolls G, Turner C (1988) Focal adhesions: transmembrane junctions between the extracellular matrix and the cytoskeleton. Ann Rev Cell Biol 4: 487-525.

Chou L, Marek B, Wagner WR (1999) Effects of hydroxyapatite coating crystallinity on biosolubility, cell attachment efficiency and proliferation in vitro. Biomaterials 20: 977-985.

Cornell R (1969) Cell substrate adhesion during cell culture. Exp Cell Res 58: 289-295.

Curtis ASG (1964) The mechanism of adhesion of cells to glass. J Cell Biol 20: 199-215.

Davies JE (1996) In vitro modelling of the bone/implant interface. Anat Rec 245: 426-445.

Degasne I, Baslé MF, Demais V, Huré G, Lesourd M, Grolleau B, Mercier L, Chappard D (1999) Effects of roughness, fibronectin and vitronectin on attachment, spreading and proliferation of human osteoblast-like cells (Saos-2) on titanium surfaces. Calcif Tissue Int 64: 499507.

Elvin P, Evans CW (1982) The adhesiveness of normal and SV40 transformed Balb C/3T3 cells: effects of culture density and shear rate. Eur J Cancer Clin Oncol 18: 669-675.

Folkman J, Moscona A (1978) Role of cell shape in growth control. Nature 273: 345-349.
Frauchiger VM (2002) Anodic Plasma-Chemical Treatment of Titanium Implant Surfaces, Doctoral Thesis, Federal Institute of Technology, Zürich, Diss ETH No. 14720. Geiger B (1999) Vinculin. In: Guidebook to the Extracellular Matrix, Anchor and Adhesion Proteins. Kreis T, Vale R, eds. Oxford University Press, Oxford. pp. 92-95.

Geiger B, Avnur Z, Kreiss TE, Schlessinger J (1984) The dynamics of cytoskeletal organisation in areas of cell contact. Cell Muscle Motil 5: 195-234.

Geiger B, Tokuyasu KT, Dutton AH, Singer SJ (1980) Vinculin, an intracellular protein localised at specialist sites where microfilament bundles terminate at cell membranes. ProcNatl Acad Sci USA 77: 4127-4131.

Gristina AG (1987) Biomaterial-centred infection: microbial adhesion versus tissue integration. Science $\mathbf{2 3 7}$ : 1588-1595.

Heath JP, Dunn GA (1978) Cell to substratum contacts of chick fibroblasts and their relation to the microfilament system. A correlated interference-reflexion and high-voltage electron microscope study. J Cell Sci 29: 197-212.

Hunter A, Archer C, Walker PS, Blunn GW (1995) Attachment and proliferation of osteoblasts and fibroblasts on biomaterials for orthopaedic use. Biomaterials 16: 287 295.

Juliano RL, Haskill S (1993) Signal transduction from the extracellular matrix. J Cell Biol 120: 577-585.

Könönen M, Hormia M, Kwilahti J, Hautaniemi J, Thesleff I (1992) Effect of surface processing on the attachment, orientation and proliferation of human gingival fibroblasts on titanium. J Biomed Mater Res 26: 1325-1341.

Krause A, Cowles EA, Gronowicz G (2000) Integrin mediated signalling in osteoblasts on titanium implant materials. J Biomed Mater Res 52: 738-747.

Mustafa K, Wroblewski J, Hultenby K, Silva Lopez B, Arvidson K (2000) Effects of titanium surfaces blasted with $\mathrm{TiO}_{2}$ particles on the initial attachment and altered cytoskeletal morphology of cells derived from human mandibular bone. Clin Oral Impl Res 11: 116-128.

Oakley C, Brunette DM (1993) The sequence of alignment of microtubules, focal contacts and actin filament in fibroblasts spreading on smooth and grooved titanium substrata. J Cell Sci 106: 343-354.

Okumura A, Goto M, Goto T, Yoshinari M, Masuko S, Katusuki T, Tanaka T (2001) Substrate affects the initial attachment and subsequent behaviour of human osteoblastic cells (Saos-2). Biomaterials 22: 2263-2271.

Owen GRh, Meredith DO, ap Gwynn I, Richards RG (2001) Enhancement of immunogold-labelled focal adhesion sites in fibroblasts cultures on metal substrates: problems and solutions. Cell Biol Int 25: 1251-1259.

Puleo DA, and Bizios R (1992) Formation of focal contacts by osteoblasts cultured on orthopaedic biomaterials. J Biomed Mater Res 26: 291-301.

Rae T (1981) Cell biochemistry in relation to the inflammatory response to foreign materials. In: Fundamental Aspects of Biocompatibility. Williams DF, ed. pp. 159181.

Richards RG (1996) The effect of surface roughness on fibroblast adhesion in vitro. Injury 27(S3): 38-43.

Richards RG, ap Gwynn I (1995). Backscattered electron imaging of the undersurface of resin-embedded cells 
by field-emission scanning electron microscopy. J Microsc 177: 43-52.

Richards RG, ap Gwynn I, Bundy KJ, Rahn BA (1995a). Microjet impingement followed by scanning electron microscopy as a qualitative technique to compare cellular adhesion to various biomaterials. Cell Biol Int 19: 1015-1024.

Richards RG, Rahn BA, ap Gwynn I (1995b) Scanning electron microscopy of the undersurface of cell monolayers grown on metallic implants. J.Mat Sci- Mat in Med 6: 120124.

Richards RG, Owen GRh, Rahn BA, ap Gwynn I (1997) A quantitative method of measuring cell-substrate adhesion area. Cells Mater 7: 15-30.

Richards RG, Stiffanic M, Owen GRh, Riehle M, ap Gwynn I, Curtis ASG (2001) Immunogold labelling of fibroblast focal adhesion sites visualised in fixed material using scanning electron microscopy, and living, using internal refection microscopy. Cell Biol Int 25 : 1237-1249.

Rodriguez Fernández JK, Geiger B, Salomon D, BenZe'ev A (1993) Suppression of vinculin expression by antisense transfection confers change in cell morphology, motility and anchorage-dependant growth of 3 T3 cells. J Cell Biol 122: 1285-1294.

Schwartz Z, and Boyan BD. (1994). Underlying mechanisms of the bone-biomaterial interface. J Cellr Biochem 56: 340-347.

Schwartz Z, Lohmann CH, Oefinger J, Bonewald LF, Dean DD, Boyan BD (1999) Implant surface characteristics modulate differential behaviour of cells in the osteoblast lineage. Adv Dent Res 13: 38-48.

Schwartz Z, Martin JY, Dean D, Simpson J, Cochran DL, Boyan BD (1996) Effect of titanium surface roughness and chondrocyte proliferation, matrix production and differentiation depends on the state of cell maturation. $\mathrm{J}$ Biomed Mater Res 30: 145-155.

Takebe J, Itoh S, Okada J, Ishibashi K (2000). Anodic oxidation and hydrothermal treatment of titanium results in a surface that causes increased attachment and altered cytoskeletal morphology of rat bone marrow stromal cells in vitro. J Biomed Mater Res 51: 398-407.

Ungar F, Geiger B, Ben-Ze'ev,A (1986) Cell contact and shape-dependent regulation of vinculin synthesis in cultured fibroblasts. Nature 319: 787-791.

Van Kooten TG, Von Recum AF (1999) Cell adhesion to textured silicone surfaces: the influence of time of adhesion and texture on focal contact and fibronectin fibril formation. Tissue Eng 5: 223-240.

Vinall RL, Gasser B, Richards RG. (1995). Investigation of cell compatibility of titanium test surfaces to fibroblasts. Injury 25: SA21-SA27

Woodward SC, Salthouse TN 1986. The tissue response to implants and its evaluation by light microscopy. In: Von Recum AF, ed. Handbook of Biomaterial Evaluation. Collier Macmillan Publ, London. pp. 364-378.

\section{Discussion with Reviewers}

P. Bongrand: It would be useful to discriminate between "contact", that is a morphological property, and "adhesion", that is a functional feature, i.e., the capacity to resist detachment by external forces. Admittedly, these features are often correlated, but it may not be always the case. It should be made clear that this paper only presents morphological data.

Authors: We believe that contact and adhesion are both functional features. We also agree that cell adhesion can be defined as the capacity to resist detachment by external forces However, there are major problems with using mechanical methods of measuring cell-substrate adhesion. An example of this is jet impingement measurement, which reveals the degree of cell adherence up until the cell/ECM interfacial strength exceeds the cell's own cohesive strength. To determine whether the failure in the cell layer is an intrinsic cohesive limit within the fibroblasts or separation at the cell/ECM or ECM/substrate interface during microjet impingement, an SEM analysis of the cellular remainders was performed. Test surfaces of steel, titanium and plastic Thermanox were used (Richards et al., 1995a). Cellular remainders, consisting of membranes, the adhesion sites and some cytoskeleton were observed where the shear forces of the impingement had ruptured the cells. This shows, with the highly adherent surfaces looked at, that cell cohesion in fibroblasts is weaker than the adhesion strength to the substrate. This reiterates the difficulty in determining the position of molecular failure in cellsubstrate adhesion measurements when mechanical techniques are used to remove cells.

Lately the use of atomic force microscope (AFM) cantilevers has become common to measure single cell detachment from the substrate. One method by Yamamoto et al. (1998) attempts to measure cell adhesive strength and cell detachment surface energy. They found differences in adhesion to varying surfaces. Analysis of the areas where cell detachment has occurred with the AFM method using interference reflection microscopy (Yamamoto et al., 2001) has shown that cell remainders are present indicating that the cell is ripped off the substrate, confirming the study by Richards et al. (1995a) using microjet impingement techniques. These results make attempts to quantify the strength of cell substrate adhesion using mechanical methods questionable. Published methods have not used either low voltage SEM to image what remains or have tried to immunolabel adhesion proteins on the substrates, after application of the mechanical disruption force, to check the validity of the technique employed. Therefore though our technique has time-resolution problems looking at one moment in time, unlike mechanical methods, which are actually measuring cell cohesion, rather than adhesion we are visualising cell adhesion at that point in time when the cell is fixed permanently.

P. Bongrand: The authors emphasise the interesting observation that cells are "raised" above APC-P or HA surfaces. Does this mean that the cell boundary is thicker on these surfaces than on others, or is possible to assess that the cell-to-substrate distance is high. 
Authors: We do not know if the cell boundary is thicker or not, but know using scanning electron microscopy that there is actually a gap between the cell membrane and substrate (in the case of APC-P or HA surfaces). If desired it could be measured using stereo imaging, but this was not of interest in this study. The cells appeared to be actively trying to keep contact to a minimum to these surfaces.

D. Brunette: Given that adhesion of some cell types can be influenced by topography could the authors provide information on the topography (ideally characterize the surfaces by the method of Wieland et al., but even a simple summary measures would be useful).

Authors: The surfaces were measured with a UBM laser profilometer (UBM Messtechnik; Hilpert Electronics, Baden-Dättwil ,Switzerland) with a microfocus ${ }^{\mathrm{TM}}$ sensor. The vertical resolution was $10 \mathrm{~nm}$ with a measurement range of $\pm 50 \mathrm{~mm}$. The scan length for each recorded profile was $1 \mathrm{~mm}$ by $1 \mathrm{~mm}$ and density of the measured points was $500 \mathrm{p} / \mathrm{mm}$. Prior to the roughness calculations, a linear regression to eliminate surface inclinations was performed on each profile. Subsequently, the waviness of the profile was subtracted with a Gauss filter with an attenuation factor of $50 \%$ according to DIN 4768 . The cut-off wavelength in the Gauss filter was set to $0.58 \mathrm{~mm}$ in accordance with Wieland (1999). The lateral resolution of the UBM was lower than the structure size of the APC surface coated in APC-P at $25^{\circ} \mathrm{C}$. This means, the measurements did not measure the APC layer. Also, for the APC surface produced in the calcium and phosphate-containing electrolyte, the laser profilometer was 'blind' for most of thesurface features (below $1 \mu \mathrm{m}$ ). A wavelength dependant roughness analysis according to Wieland et al., (2000; 2001) unfortunately does not really make sense for the data obtained from the UBM measurements since the interesting range of the wavelengths is missing (i.e., the range characteristic for the APC structures).

$\begin{array}{lrcclccl} & \text { HA } & \text { PA-25 } & \text { PA-75 } & \text { Th } & \text { Ti } & \text { V200 } & \text { V290 } \\ \text { Ra } & 4.19 & 0.57 & 0.55 & 0.1 & 1.17 & 0.5 & 0.51 \\ \text { Rmax } & 39.68 & 7.17 & 7.05 & 3.16 & 15.07 & 6.4 & 6.26 \\ \text { Rt } & 42.95 & 7.17 & 7.05 & 3.72 & 15.07 & 6.43 & 6.3 \\ \text { RzDIN } & 35.69 & 6.65 & 6.36 & 2.66 & 12.85 & 6.0 & 5.9\end{array}$

Ra- centre line average height or arithmetic average of the absolute values of all points of the profile. Rmax - Maximum individual roughness depth. Rt- Maximum peak to valley height of entire measurement or maximum roughness. RzDIN- is the mean peak to valley height or averaged profile depths.

D. Brunette: Could the authors comment on how the varying topographies may have influenced their results? I am aware that the conditions are such that they cannot precisely differentiate between the effects of topography and chemistry, but it could be discussed.

Authors: Numerous studies show that different surface properties, including adhesiveness (Hallab et al., 1995), flexibility (Pelham and Wang, 1997), chemistry and topography (Britland et al., 1996) and even the crystallinity of surfaces with identical chemistry (Boyan et al., 1996) affect the morphology and adhesion of cells. There were three surfaces with similar chemistry, the HA (consisting of calcium phosphate) and the two APC-CaP, but which induced very different cell responses. Chou et al. (1999) had results when using different calcium and phosphate concentrations in a hydroxyapatite surface, where they believed the surface chemistry did not affect osteoblast adherence. Topography, however, may be a more influential factor. A study using a combination of surface chemistry and topography (Britland et al., 1996) shows that the balance between these two factors influences the orientation or rat dorsal root nerve cells. Britland et al. (1996) used a chemical cue (laminin) orientated at $90^{\circ}$ to topographical grooves in the substrate the cells are attached to. It is shown that there is a direct correlation between the depth of the grooves and the orientation of attached cells. A greater orientation to the chemical cue on the surface with shallow grooves $(<500 \mathrm{~nm}$ deep $)$ is observed, but as the depth of the grooves increased to $5 \mathrm{~nm} 80 \%$ of the cells are observed to be orientated along the grooves.

D. Brunette: The finding that cells did not spread on the HA surface is surprising for (as noted by the authors) several investigators have found good spreading of cells on HA surfaces. Could the procedure used to sterilize the surfaces have affected cell adhesion?

Authors: Gamma sterilisation is known to affect ultra high molecular weight polyethylene (UHMWPE) with delamination, oxidation and cracking, resulting in reduced mechanical properties of ductility, toughness and cyclic fatigue strength. Since gamma rays cause ionisation of cellular components, including nucleic acids, resulting in death of microbes, gamma irradiation could not be used for organic coatings. It is not thought to affect either metal or calcium phosphate coatings and is used for both as standard practice for sterilisation of orthopaedic implants by Mathys Medical (Bettlach, Switzerland), Stratec Medical, and Synthes USA (Paoli, PA, USA). Previously implant quality $316 \mathrm{~L}$ stainless steel has been subjected to 2.5-3.2 mrad gamma radiation and compared the hardness, microstructure, and grain size to an un-sterilised sample to satisfy an FDA inquiry. No differences were observed (Personal communication with Synthes USA).

D. Brunette: The authors note that the gold labelling was harder to locate in cells imaged from above than from below. Once located, did images taken from above and below yield similar data? The question arises from a practical concern that the gold labelling technique would probably be used more widely, if it could be effectively employed when adhesions were observed directly on the surfaces rather than fractured off the substrates.

Authors: On non-metal biomaterial surfaces, such as plastics, polymers and ceramics, quantification of gold labelling could easily be carried out directly from above, since there is a high degree of contrast between the gold and substrate. The problem is that vinculin exists not only in the focal adhesion but also in the cell cytoplasm, which is also labelled, should not be measured and cannot be separated from the focal adhesion vinculin when imaging from above. After embedding and removal of the substrate and 
imaging using 'electron energy sectioning' (Richards and ap Gwynn, 1995) at low energy only the focal adhesion vinculin is imaged. Future development of this technique (currently under investigation) will be to use confluent cell layers, rather than individual cells that will considerably reduce the amount of manual work required in imaging and image analysis, which should open the technique to all.

\section{Additional References}

Britland,S, Perridge C, Denyer M, Morgan H, Curtis A, Wilkinson C (1996) Morphogenetic guidance cues can interact synergistically and hierachically in steering nerve cell growth. Exp Biol Online 1:2.

Hallab NJ, Bundy KJ, O'Connor K, Clack R, Moses RL (1995) Cell adhesion to biomaterial: correlations between surface charge, surface roughness, absorbed protein and cell morphology. J Long Term Eff Med Implants 5: 209-231.

Pelham RJ, Wang Y-L (1997) Cell locomotion and focal adhesions are regulated by substrate flexibility. Proc
Natl Acad Sci 94: 13661-13665.

Wieland M (1999) Experimental Determination and Quantitative Evaluation of the Surface Composition and Topography of Medical Implant Surfaces and their Influence on Osteoblastic Cell-Surface Interactions. Doctoral Thesis: Federal Institute of Technology, Zürich. Diss ETH No. 13247.

Wieland M, Hanggi P, Hotz W, Textor M, Keller BA, Spencer ND (2000) Wavelength-dependent measurement and evaluation of surface topographies: application of a new concept of window roughness and surface transfer function. Wear 237: 231-252.

Wieland M, Textor M, Spencer ND, Brunette DM (2001) Wavelength-dependent roughness: A quantitative approach to characterizing the topography of rough titanium surfaces. Int J Oral Maxillofac Implants 16: 163-181.

Yamamoto A (2001) Biomechanics of cell-material adhesion. Eur Cells Mater 2 (S1): 11-12.

Yamamoto A, Mishima S, Maruyama N, Sumita M (1998) A new technique for direct measurement of the shear force necessary to detach a cell from a material. Biomaterials 19: 871-879. 